\title{
Artes de governo, anarqueologia e assinaturas na geração de modelos analíticos no campo da Administração educacional
}

\author{
Arts of government, anarcheology and signatures in the generation of analytical \\ models in the field of Educational Administration \\ Artes de gobierno, anarqueología y firmas en la generación de modelos \\ analíticos en el campo de la Administración educativa
}

ALEXANDRE SIMÃO FREITAS

Resumo: $\mathrm{O}$ artigo assume a noção de governamentalidade como ferramenta teórica fundamental na análise das categorias que estruturam as teorias administrativas em educação na atualidade. O objetivo consiste em desdobrar metodologicamente uma anarqueologia dos saberes da Administração educacional, seguindo as análises de Michel Foucault e Giorgio Agamben sobre o poder pastoral e a teologia econômica. Como resultado, delineia-se uma leitura alternativa sobre a subsunção recente do conceito de administração pelos paradigmas de gestão no contexto da globalização neoliberal.

Palavras-chave: Governamentalidade; anarqueologia; Administração educacional.

\begin{abstract}
The article assumes the notion of governmentality as a fundamental theoretical tool in the analysis of the categories that structure the administrative theories in education today. The objective is to unfold methodologically an anarchaeology of the knowledges of the Educational Administration, following the analyzes of Michel Foucault and Giorgio Agamben on pastoral power and economic theology. As a result, an alternative reading is delineated about the recent subsumption of the concept of management by administration paradigms in the context of neoliberal globalization.
\end{abstract}

Keywords: Governmentality; anarchaeology; Educational administration.

Resumen: El artículo asume la noción de gubernamentalidad como una herramienta teórica fundamental en el análisis de las categorías que estructuran las teorías administrativas en educación en la actualidad. El objetivo consiste en desplegar metodológicamente una anarqueología de los saberes de la Administración educativa, siguiendo los análisis de Michel Foucault y Giorgio Agamben sobre el poder pastoral y la teología económica. Como resultado, se delinea una lectura alternativa sobre la subsunción reciente del concepto de administración por los paradigmas de gestión en el contexto de la globalización neoliberal.

Palabras clave: Gubernamentalidad; anarqueología; Administración educativa. 


\section{INTRODUÇÃO}

A ênfase nos paradigmas de gestão no contexto da globalização neoliberal parece reiterar a tese de Agamben (2011, p. 8), segundo a qual "não podemos entender o triunfo da economia hoje em dia se não o entendemos ao mesmo tempo como triunfo do paradigma gerencial da oikonomia teológica". Assim, propomos reconstruir nesse artigo uma espécie de história esquecida das categorias que estruturam as teorias administrativas em educação, elucidando, nesse percurso, sua subsunção recente aos chamados paradigmas de gestão.

Trata-se de uma reflexão teórica motivada pela escassez de estudos voltados para os fundamentos ontológicos das teorias administrativas no campo educacional. Os poucos trabalhos existentes nessa direção se propõem, antes, um resgate histórico das transformações da disciplina também denominada Administração educacional e/ou escolar (MESSAS, 2007; MAYER; CANOPF, 2006; DRABACH; MOUSQUER, 2009) ${ }^{1}$.

Nesse último âmbito, focaliza-se o estudo da Administração Educacional por meio de duas tendências antagônicas: a primeira, defendendo a transposição dos princípios, métodos e técnicas emanadas das Teorias Gerais da Administração; e a segunda, lutando pela especificidade da educação como base da Administração educacional e escolar.

Essas mesmas pesquisas tendem a agrupar a história da Administração educacional brasileira em três grandes momentos. O primeiro, dos anos 1930 até os anos 1970, caracteriza-se pela defesa epistêmica do campo, apoiada principalmente em teorias administrativas gerais e tendo como base os estudos dos chamados pioneiros (TEIXEIRA, 1956; RIBEIRO, 1978)². O segundo, de meados dos anos 1970 até os anos 1980, destaca-se pela crítica ao modelo burocrático de organização escolar (TRAGTENBERG, 1980; 1974; ALONSO, 1978). Nesse período, consolidam-se os estudos voltados à constituição de uma teoria da administração educacional em bases próprias (FÉLIX, 1989; PARO, 1999), questionando-se a correlação entre a administração empresarial e a educacional.

1

Não se trata de desconhecer a importância dessas tentativas, pois, como sabemos, ainda é patente a influência de outras áreas sobre a teoria e a prática da Administração educacional, o que contribui para sua subordinação epistêmica, bem como para a obstrução da especificidade crítica do campo (SANDER, 1982; 1985; WITTMANN, 1987; 1985).

2 Para uma análise específica do papel dos pioneiros da Administração da educação (Antonio Carneiro Leão, José Querino Ribeiro, Manoel Lourenço Filho), no Brasil, veja-se a pesquisa de Ribeiro e Machado (2007). 
Por fim, no terceiro momento, dos anos 1990 até o presente, a produção da área passou a ser marcada por novas concepções de democracia e administração pública (BRUNO, 1997), confluindo na centralidade do princípio da gestão democrática. A tônica, contudo, é fornecida pelos debates sobre a globalização, a descentralização e o financiamento da educação, questões que surgem hegemonizadas pela questão da qualidade (ALGARTE, 1998), reverberando o diagnóstico de que estaríamos vivendo uma "estagnação teórica da administração educacional” (SILVA JÚNIOR, 2002, p. 199).

De fato, a primeira década deste século foi pouco ou nada propícia ao desenvolvimento sistemático de estudos teóricos de fôlego. Contrariando a expectativa não confirmada de que as análises ancoradas em um referencial com forte inspiração histórico-crítica geraria uma delimitação teórica-conceitual do campo, após breve revitalização da produção acadêmica largamente influenciada pela crítica à perspectiva neoliberalista na educação, as pesquisas teóricas praticamente desapareceram.

Desse modo, seguindo Kuenzer (1984), admite-se a importância de avançar para além dos estudos históricos, dimensionando o próprio uso dos conceitos que são mobilizados pela Administração educacional brasileira. O que não significa recolocar o debate no estatuto de sua cientificidade, pois essa postura analítica tende a priorizar reflexões em um eixo epistemológico que contribui para reiterar uma visão naturalizada do saber científico na qual a verdade estaria inscrita no próprio objeto de estudo.

Esse tipo de abordagem legitima processos de despolitização dos saberes na área, ao mesmo tempo em que evidencia uma ausência de diálogo com as reflexões da Filosofia Política contemporânea, um campo gravemente subestimado pelos pesquisadores da Administração educacional (TORRES, 1992), mas que estuda as relações de poder estruturadas nos vários níveis da organização social. A ausência de uma interlocução sistemática com esses aportes produz uma subteorização das análises, tendo como resultado investigações assombradas por sua própria inconsistência conceitual, pois os fundamentos normativos da Administração educacional "não foram completamente elaborados" (p. 22).

Ao radicalizar esse posicionamento, o presente texto visa justamente a mobilizar os estudos sobre a governamentalidade para um entendimento genealógico da formação do campo de saberes que estruturam as teorias administrativas em educação. 
Nessa direção, admite-se que o pensamento tardio de Foucault fornece pistas importantes para uma reflexão renovada da razão de Estado moderna ${ }^{3}$, a partir do que ele denominou de anarqueologia dos saberes. Uma análise genealógica que nos libera das constrições geradas pelas teorias sociológicas, comumente usadas pelos pesquisadores do campo, e que "dão ao Estado a imagem de uma realidade unificada" (AVELINO, 2010, p. 03). A anarqueologia abdica de investigações geradas em termos de soberania, legitimidade ou representação, focando a conceitualização das próprias práticas de governo.

Dessa ótica, a questão movente consiste em investigar em que medida o estudo da governamentalidade política estatal, efetuada por autores como Foucault e Agamben, possibilita, implica e demanda uma anarqueologia das teorias administrativas que lhe são associadas no campo da educação e da formação humana, a fim de que se possa recusar os processos biopolíticos de controle neoliberalista vigentes na educação.

A exposição foi construída a partir de uma pesquisa bibliográfica ancorada no curso Segurança, Território e População (FOUCAULT, 2008), e na obra de Agamben (2011), O Reino e a Glória. A leitura desses textos permitiu demonstrar as afinidades entre aquilo que Foucault chamou de poder pastoral, ou seja, o poder de produzir sujeitos governáveis a partir da captura de sua subjetividade, e o que Agamben (2011) descreveu nos termos de uma "história das ideias teológicas que alimentam nossas teorias administrativas" (p. 13).

\section{AS NOVAS “ARTES DE GOVERNAR” E A RAZÃO DE ESTADO MODERNA}

Nos seus trabalhos tardios, Michel Foucault dedicou parte significativa de suas investigações à exploração de uma imensa literatura sobre as artes de governar. Um corpus caracterizado em oposição a obras como O Príncipe de Maquiavel, e cujo contexto imediato era fornecido pelo sentimento de perigo social gerado pelas tensões violentas que ameaçavam a paz das vilas provocadas pela escassez de alimentos.

3 Na literatura disponível encontram-se dois significados gerais do termo governamentalidade. O primeiro, referido como artes de governar, é mais geral e aponta uma abordagem do Estado moderno. $\mathrm{Na}$ segunda definição, o termo é pensado a partir da fusão entre as noções de governar (gouverner) e mentalidade (mentalité), salientando a interdependência entre o exercício do governo (suas práticas) e as mentalidades (racionalidades políticas). Trata-se de uma noção criada por Foucault e desdobrada por autores como Dean (1999), Gordon (1991), Lemke (2000) e Rose (1999). No campo educacional, estudos inspirados nessa noção incluem os trabalhos de Ball (1990; 1994), Peters (2001; 2003) e Tikly (2003). 
Mas, no final do século XVII, as revoltas camponesas vão reduzindose e os conflitos desviando-se para o interior da vida urbana, dando origem a um novo medo articulado em torno das epidemias e revoltas que ameaçam as cidades, o que desdobra mecanismos de esquadrinhamento do espaço urbano e de vigilância dos hábitos dos cidadãos (FOUCAULT, 2008). É nesse mesmo cenário que emerge o discurso em torno da urgência do ensino para todos, a partir de uma nova composição entre os diversos tipos de governo: governo do poder estatal; governo do patrimônio na vida privada; governo de si no campo moral; e governo das crianças que se tornará o tema privilegiado da pedagogia.

O poder estatal se configura, nesse âmbito, como mais uma das formas de governo, referindo-se às múltiplas sujeições que ocorrem e funcionam no interior do corpo social. As artes de governar modernas não tratam nem se limitam a impor a lei, ocupando-se com o modo correto de dispor pessoas e coisas para conduzi-las a fim de alcançar objetivos múltiplos e variáveis, tais como: produzir mais riquezas, controlar a explosão demográfica, evitar as epidemias, conter as rebeliões, educar as crianças, etc. Para atingir esses diferentes fins, é preciso usar mais táticas do que leis, ou melhor, usar as normas e as leis como táticas móveis. Assim, diz Foucault (1992, p. 292), desde o século XVII, vivemos na era da governamentalização do Estado, "um fenômeno astucioso" que garante a sobrevivência do próprio Estado por meio de medidas que definem "o que deve ou não competir ao Estado".

O argumento foucaultiano lembra, ainda, que o controle político das populações não se opera meramente pela consciência ou pela ideologia, mas pelo investimento maciço em um corpo domesticado. A política escolar, por exemplo, vai constituir um conjunto de estratégias de disciplinarização anátomo-política dos corpos, instaurando um novo dispositivo de seleção e normalização das condutas (FOUCAULT, 2013). O problema central é como fazer para que os governos cobrem da parte dos que são dirigidos mais do que atos de obediência. Nessa direção, a razão de Estado moderna desdobra um tipo excêntrico de governo no qual não se é solicitado apenas a obedecer, mas, sobretudo, a manifestar aquilo que se é. Governar passa a significar um processo complexo de condução das condutas que almejam levar indivíduos e populações a manterem suas crenças, seja aceitando a autoridade que as autentica, seja vivendo em conformidade com elas, por meio de um novo governo da verdade, onde a verdade deixa de ser pensada como algo apenas da ordem da lógica, configurando-se mais como uma forma específica de engajamento.

Esse novo governo da verdade é representado, por Foucault (2010, p. 155), através da expressão: "é verdade, logo, eu me inclino". Sem dúvida, este "logo" é uma proposição um tanto "enigmática", pois nele existe qualquer coisa 
que "não pertence à verdade em si mesma" e que a ciência "não pode justificar e dar conta" (p. 156). O problema é que a Filosofia política da qual somos herdeiros naturalizou outra conjunção colocada entre o "eu penso" e o "eu existo". A famosa experiência do cogito cartesiano ocultou uma conjunção mais prosaica, na qual se fazem presentes determinados regimes de verdade que são irredutíveis às leituras epistêmicas, pois fala das condições para a aceitação de um dado regime de verdade pelos próprios sujeitos que o enunciam, vinculando-os ao jogo político da verdade.

Cada sociedade tem seu regime de verdade, sua "política geral de verdade": isto é, os tipos de discurso que ela acolhe e faz funcionar como verdadeiros; os mecanismos e as instâncias que permitem distinguir os enunciados verdadeiros dos falsos, a maneira como se sancionam uns e outros; as técnicas e os procedimentos que são valorizados para a obtenção da verdade; o estatuto daqueles que têm o encargo de dizer o que funciona como verdadeiro (FOUCAULT, 2014, p. 12).

É por meio desse curioso movimento interpretativo que Foucault introduziu uma postura anarqueológica (AVELINO, 2012) fundamental para os propósitos de uma reconstrução das categorias que embasam as teorias administrativas em educação na atualidade, uma vez que a anarqueologia dos saberes não visa à história de uma ciência para demonstrar a validade de seus conceitos e teorias. Trata-se de mostrar, ao contrário, como os sujeitos estão presos a procedimentos específicos de manifestação do verdadeiro que são reiterados e reproduzidos por meio de vários saberes científicos ou não.

A investigação anarqueológica vai ao encontro do que Agamben (2011, p. 16) chama de assinaturas, pois todo conceito está atravessado por marcas que indicam transferências e deslocamentos de significados e signos de uma esfera para outra. Uma assinatura seria algo que, em determinado conceito, o marca e o excede-o para remetê-lo a um novo âmbito, constituindo novos sentidos e instaurando novos usos.

A pertinência de uma história das assinaturas reside no fato de que nossos conceitos políticos modernos mantêm ativadas, tensões e patologias sociais de longo alcance. Uma história rigorosa é capaz de identificar problemas perenes e nos informar dos perigos inerentes à teologização do político que subjaz na idealização de qualquer conceito (HERVÁS, 2010, p. 75).

Esse procedimento teórico-metodológico demonstra toda sua pertinência quando se interroga o modo como as teorias administrativas em educação problematizam o poder governamental, sob a rubrica limitativa do chamado poder executivo. Para autores como Foucault e Agamben, ao contrário, o verdadeiro arcano da política e das teorias administrativas é justamente a noção 
de governo. Para evidenciar os efeitos desse posicionamento, ambos colocam em jogo a centralidade da teologia cristã como espaço de refração analítica das noções que estruturam nossa compreensão do poder político.

\section{O PODER PASTORAL COMO PONTO CEGO DAS TEORIAS ADMINISTRATIVAS EM EDUCAÇÃO}

No curso Segurança, território, população, Michel Foucault desenvolveu uma analítica da figura do pastor e suas repercussões nas práticas governamentais. Para ele, o poder pastoral seria uma espécie de matriz das artes de governo dos homens, vigentes na razão de Estado moderna. O pastor é aquele que exerce seu poder a fim de alcançar cada indivíduo em sua singularidade, ao mesmo tempo em que deve prover tudo o que é necessário para satisfazer as necessidades do rebanho no seu conjunto. O governante pensado como um pastor deve colocar sua atenção nos indivíduos que compõem o rebanho, embora precise considerálos em seu conjunto. Por outro lado, como se trata de um governo de seres vivos em movimento, o poder pastoral não se exerce sobre um território, visando antes a conduzir "uma multiplicidade em movimento" (FOUCAULT, 2008, p. 154).

Esse duplo aspecto distributivo e paradoxal do poder pastoral, "omnes et singulatim", nos termos de Foucault (2006), será o grande problema do poder moderno, pois exige colocar em ação técnicas administrativas especificamente voltadas a identificar, corrigir e regulara presença de irregularidades no ordenamento social. O pastorado destrava um sofisticado poder normalizador que se estende para vários domínios. Na educação, os processos de normalização substituem ou acrescentam "graus de normalidade" (PORTOCARRERO, 2004, p. 175), que, por sua vez, se convertem em "signos de pertença a um corpo social" (ibidem). A normalização atua constrangendo "para homogeneizar as multiplicidades, ao mesmo tempo que individualiza, porque permite as distâncias entre os indivíduos, determina níveis, fixa especialidades e torna úteis as diferenças" (ibidem).

Em síntese, o poder pastoral funciona através de uma dupla captura: instituindo normas que objetivam o sujeito, e subjetivando os sujeitos por meio dessas normas. Sem o poder normalizador próprio ao pastorado, diz Foucault (2008), a economia política não teria como prevalecer como paradigma de governo das populações na modernidade.

No entanto, o poder pastoral também fez recair algumas exigências sobre quem governa, que precisa demonstrar uma disposição considerada essencial para aquele que administra uma população, pois “aquele que governa, somente deve governar à medida que vá considerar-se e agir como se estivesse ao serviço dos governados" (FOUCAULT, 2008, p. 127). Ou seja, o pastorado é um modo 
estratégico de governo que não impõe a lei mediante a força, mas pondo-se ao serviço dos próprios governados. Desse modo, o governante, seja ele um político ou um professor, precisa adotar-demonstrar a atitude de alguém que trabalha para o bem comum, isto é, para atender os interesses dos governados.

$\mathrm{Na}$ modernidade, o poder pastoral desdobrou um conjunto de saberes, dentre os quais destacam-se a estatística ${ }^{4}$ e a polícia $^{5}$, que possibilitaram expandir a influência do pastorado para o interior da estrutura governamentaladministrativa, trazendo à tona o primeiro foco de experiência onde se pode visualizar a emergência dos principais conceitos e práticas que constituirão, no século XX, a administração científica da educação. Assim, a educação passa a ser pensada como condução de um conjunto de indivíduos; condução embasada em conhecimentos que deveriam levar em conta regularidades comportamentais a serem implementadas por meio de técnicas como "vigilância hierárquica", "sanção normalizadora" e "exames" (FOUCAULT, 2013, p. 164). O objetivo é "docilizar os corpos", eliminando-se os castigos e as punições físicas. O educador devendo fazer valer sua vontade por meio de uma "arte das distribuições" (p. 137) das tarefas desempenhadas no interior da instituição escolar, planejando as atividades no espaço e no tempo.

A educação torna-se, ela mesma, um dispositivo cuja finalidade é inserir os alunos no mundo do trabalho capitalista, com o argumento de que assim o Estado atuaria para prover suas necessidades básicas. No conjunto, os novos processos administrativos que passam a vigorar nas instituições educativas pretendem modificar as maneiras de viver e de agir dos indivíduos tanto como sujeitos econômicos, como enquanto sujeitos políticos.

A analítica foucaultiana do poder pastoral deixa claro, então, como uma genealogia das teorias administrativas em educação deve começar pelos modos como crianças e jovens foram consideradas um alvo prioritário de exercício do poder político, transformando-as em sujeito-objeto de um poder-saber que visa a

$4 \quad$ Foucault nos mostra que a emergência política da estatística, como saber do Estado, tem como finalidade conhecer as diferentes forças através da aplicação de uma racionalidade econômica, cuja meta é o crescimento infinito das riquezas e a proteção da soberania do próprio Estado (FOUCAULT, 2008, p. 365).

Diferindo da significação que se atribui hoje, entre o século XVII e o fim do século XVIII, o conceito de polícia definia os meios pelos quais a potência do Estado poderia crescer ao mesmo tempo em que era garantida a manutenção da ordem em seu interior. Uma intrigante teoria da polícia se fez presente nos principais manuais para administradores que estivessem à frente do Estado. O Traité de la police, de Nicolas Delamare, por exemplo, designava treze domínios que a polícia deveria gerir: "a religião, os costumes, a saúde e os meios de subsistência, a tranqulidade pública, o cuidado com os edifícios, as praças e os caminhos, as ciências e as artes liberais, o comércio, as manufaturas e as artes mecânicas, os empregados domésticos e os operários, o teatro e os jogos, enfim o cuidado e a disciplina dos pobres" (FOUCAULT, 2008, p. 450). 
conduzi-las através da produção de uma verdade sobre elas mesmas, permitindo que o Estado interfira nos seus desejos, comportamentos e opiniões. Convertendose a população escolar em uma figura secularizada do rebanho:

Cuidar bem da população é sinônimo de potenciar a riqueza do Estado. Este cuidado é em si mesmo paradoxal porque se cuida da população enquanto esta significa riqueza real ou potencial para o Estado. Porém, quando essa população se tornar inútil, o Estado tenderá a suspender o cuidado sobre ela e a abandonará à sua sorte (AGAMBEN, 2004, p. 34).

Isso mostra que a emergência dos saberes e práticas administrativas acompanham o movimento de inclusão da categoria povo na nova categoria população. O povo sendo concebido formalmente como sujeito de direitos e a população forjada realmente como objeto de governos múltiplos e variáveis. A noção de população, na verdade, delimita as vidas que devem ser governadas enquanto um recurso vital a ser instrumentalizado pelas técnicas gerencialistas concernentes. A tensão povo-população não é mera abstração filosóficoeducacional, indicando as razões para o empresariamento crescente das formas de vida e a subsunção das teorias administrativas em educação nos paradigmas de gestão.

\section{A GENEALOGIA TEOLÓGICO-POLÍTICA DO GOVERNO E AS APORIAS DA GESTÃO EDUCACIONAL}

Para entender melhor esse argumento, acompanhemos as análises de Giorgio Agambem em O Reino e a Glória. Nessa obra, o filósofo italiano oferece uma análise sui generis para os pesquisadores das teorias administrativas em educação, ao focalizar o fenômeno da secularização da economia teológica e a sacralização litúrgica da política.

Seguindo a trilha dos estudos genealógicos foucaultianos, Agamben (2011, p. 31) ajusta o foco para os primeiros séculos da teologia cristã, explorando como a ressignificação do termo grego oikonomia produziu uma série de transmutações conceituais que culminaram na visão moderna do governo político como mero poder executivo.

A teologia cristã, diz Agamben, destituiu a dimensão propriamente ontológica da política, equiparando-a e reduzindo-a ao âmbito da economia compreendida como "gestão das coisas e dos corpos". Esse deslocamento revela a base teológica oculta do paradigma do poder político moderno como um autêntico paradigma administrativo-gestionário, uma vez que ao transferir o conceito grego de oikonomia do seu sentido original de "ciência da administração doméstica" para 
a concepção de um "governo divino do mundo", os primeiros teólogos cristãos passaram a legitimar a ação do governante desde uma solidariedade sutil com o livre-arbítrio das criaturas, ou seja, todo governo que governa as pessoas como se elas governassem a si mesmas é considerado um governo legítimo.

Mas esse gesto de "tradução" permitiu também que a teologia abandonasse o "campo religioso para imiscuir-se no mundo, e notadamente no mundo político" (AGAMBEN, 2011, p. 17), modificando estruturalmente o sentido da antiga distinção entre ordenatio e executio, hoje declinada em pares complementares como: lei e polícia, poder constituinte e poder constituído. Todos esses pares dicotômicos remontam à diferenciação teológica entre providência "geral" e "especial", isto é, entre uma providência identificada com o funcionamento do mundo em suas linhas essenciais (ordenatio) e outra identificada com um governo do mundo desde a imanência de suas contingências (executio), configurando a "máquina bipolar" da soberania política que passou a ser articulada em dois níveis distintos, a fim de assegurar tanto a autonomia do governante perante o mundo quanto a possibilidade de sua intervenção providencial no mesmo. Analogamente, na modernidade, a distinção entre Estado e governo reproduz a estrutura dessa máquina, e o governo passa a ser entendido como uma atividade burocrática da administração ${ }^{7}$.

Mas, é sobretudo na análise do ato litúrgico que Agamben revela o ânimo teológico de nossas principais categorias político-administrativas. Assim como os teólogos cristãos já haviam feito com a noção de oikonomia, o termo grego leitourgia foi expropriado do seu significado preciso de prestações comunitárias que os cidadãos deveriam fazer em prol da polis, para assumir um caráter cultual expresso exemplarmente no ato de louvor.

Os cânticos de louvor e glória passaram a definir a essência mesma da liturgia cristã, expressando uma relação política originária através da qual os servos se vinculam a seu senhor ${ }^{8}$. Nessa direção, Agamben (2011, p. 193) identifica a glória como o segredo pontual do poder de governar em sua dimensão propriamente gerencial. Isso porque as "aclamações ritualísticas", apreendidas enquanto "formas litúrgicas da Glória", atuam diretamente na legitimação do poder instituído. A liturgia cristã não se configurava como mera “expressão subjetiva de

6 Nos escritos de teólogos como Hipólito, Tertuliano e Gregório de Nazianza, Agamben (2011, p. 8) identifica como o conceito de "economia" foi sendo conjugado com o de "providência", fornecendo ao "governo da realidade" um modelo segundo o qual Deus "governa tudo irresistivelmente, mas com brandura e sem violência, de modo que o homem crê seguir sua vontade enquanto executa a de Deus”.

$7 \quad$ Desse modo, o governo jamais se identifica plenamente com o Estado, "assim como a pessoa do Filho jamais se identifica plenamente com a pessoa do Pai na economia trinitária” (AGAMBEN, 2011, p. 18).

8 O termo leitourgia se origina a partir de dois outros substantivos: laos, povo, e ergon, referindo-se aos serviços públicos que os cidadãos devem fazer enquanto cidadãos (AGAMBEN, 2011, p. 11). 
louvor"; as celebrações eram políticas na medida em que tinham verdadeiramente uma "função instituinte", pois cabia aos cultos coletivos o poder de reconhecer a ekklesia como um espaço diferenciado dos outros lugares particulares ou sociais, antecipando no tempo a concepção burocrática do poder governamental.

A função instituinte da liturgia cristã fez confluir aclamação política e opinião pública, desdobrando o princípio formal da representação que, como sabemos, só pode ser executado com a condição de que haja um público. Assim, por trás da teoria de legitimação do poder através do sufrágio individual, universal e secreto, Agamben (2011, p. 277) identifica uma máquina de produção de consensos e aclamação glorificante assentada nos mecanismos de formação da opinião pública. Essa máquina incorpora, gradativamente, os meios de comunicação de massa, a fim de gerenciar a dimensão aclamativa do poder.

Em outros termos, os meios massivos de comunicação carregam "uma nova potência política" que "deriva do modo como a opinião pública avalia, aprova ou desaprova qualquer ato de governo" (RUIZ, 2014, p. 207), concentrando o poder de disseminação própria à teologia da glória e configurando o próprio "ser da opinião pública”. A consequência imediata dessa situação é uma diluição dos âmbitos público e privado à medida em que as mídias formatam a percepção e o modo como as pessoas pensam.

Esse diagnóstico nos faz tropeçar nas principais aporias que articulam o governo político nas sociedades modernas. A glória (midiática) revela a vacuidade constituinte dos poderes vigentes, uma vez que os governos passam a legitimarse através da midiatização crescente da opinião pública que, glorificando suas decisões, garante sua continuidade indefinida na medida em que sejam capazes de produzir uma opinião pública favorável ${ }^{10}$.

A transformação do poder em espetáculo e do espetáculo em meio aclamatório de legitimação do poder coloca as atuais versões das democracias em uma posição aporética. Afirmam-se aporeticamente como democracias [poder do povo] enquanto desenvolvem, concomitantemente, dispositivos de fabricação de opinião pública, produzem formas de glorificação que, através do consenso maioritário, legitimam sua permanência no espaço e no tempo. Esses dispositivos, e com eles o poder das democracias, são altamente dependentes do poder espetacular, do espetáculo bem sucedido do poder (AGAMBEN, 2011, p. 279).

9 Por essa razão, na teologia cristã sempre se fez uma distinção qualitativa fundamental entre a liturgia e as devoções particulares. Estas seriam individuais e não expressariam o ser da ekklesia, enquanto a liturgia não só celebra, senão que institui a ekklesia (AGAMBEN, 2011, p. 193).

10 Na mesma direção, a ideologia liberal ou neoliberal consegue impor-se de modo bastante eficaz. Mas o diferencial do neoliberalismo é o fato de esse último argumentar, carregado por certa hybris, que o "fim da história" já chegou, uma vez que o Reino da economia mercantil já está completamente materializado, restandonos apenas cantar sua Glória nas litanias cotidianas da publicidade e do consumo (SORDI, 2013). 
Aqui, não restam dúvidas, o paradigma governamental que move a política moderna e contemporânea torna-se rigorosamente infernal, eternizando uma forma de poder que passa a atuar através da gestão midiática das crises que ele mesmo engendra. A constância das crises, aliás, é o que autoriza o estado de exceção a que estamos sujeitos. A crise transforma-se em nossa sacralidade cotidiana. Como resultado, os processos de gestão dos homens e do próprio Estado deixam de ser alvos específicos de problematização, fazendo com que a cada crise anunciada, clamem-se e se aclamem os novos choques de gestão. Daí Agamben (2011), afirmar não ser possível entender o triunfo da economia e do neoliberalismo se não se entende que o problema de todo governo implica a generalização de um paradigma de gestão, "cujas origens remontam à oikonomía teológica" (p. 299).

Se hoje assistimos ao domínio arrasador do governo e da economia sobre uma soberania popular esvaziada de qualquer sentido, isso significa talvez que as democracias ocidentais estejam pagando as consequências políticas de uma herança teológica que, por intermédio de Rousseau, assumiram sem se dar conta (AGAMBEN, 2011, p. 302).

Nesse contexto, a indistinção entre governo e poder executivo assume consequências trágicas, permitindo que a reflexão política se extravie "por detrás de abstrações e mitologemas vazios como a Lei, a vontade geral e a soberania popular, deixando sem resposta precisamente o problema político decisivo" (AGAMBEN, 2011, p. 299): o problema da própria máquina governamental e suas técnicas de gestão da vida.

Assim como já havia sinalizado Foucault (2008), o governo dos vivos no ocidente evoca uma forma de poder que introduz, continuamente, a economia na práxis política, denotando que a finalidade substancial de todo governo é o controle biopolítico das populações. Nesse sentido, tanto o pastorado eclesial como o governo político estatal moderno estão enredados no interior de um paradigma econômico-administrativo.

Esse diagnóstico mostra a urgência de se redimensionarem as bases conceituais e normativas das teorias administrativas em educação, uma vez que elas tendem a obstruir as concepções teológicas do poder político que as fundamentam e legitimam. Um exemplo dessa situação é o caráter ambivalente, para dizer o mínimo, da "mudança terminológica" recente do campo conceitual da administração para gestão educacional (CALIXTO, 2008).

Essa mudança aparentemente inócua de léxico, do ponto de vista aqui adotado, pode estar contribuindo para invisibilizar as novas estratégias políticas de controle da vida, apontando uma ordem discursiva que altera as relações entre 
educação e democracia (POLI; LAGARES, 2017, p. 835). Logo, não é casual que o uso e a defesa da noção de gestão, pela própria administração pública, tenha adquirido o estatuto de uma verdadeira potência formativa, veiculando um novo consenso configurado exemplarmente nas parcerias crescentes entre o Estado, as empresas e as organizações da sociedade civil.

Contudo, o uso inflacionado do termo gestão mais do que expressar uma ruptura efetiva no campo teórico-prático da administração educacional, apreendida agora como mais um elemento da gestão (sinônimo de gestão administrativa), instala uma nova polaridade entre uma administração educacional, técnica e potencialmente autoritária, e uma gestão, imanentemente democrática e contigencialmente gerencialista. Esse posicionamento difunde a crença equívoca de que o termo gestão se configura como uma espécie de "evolução natural" dos paradigmas da administração educacional ${ }^{11}$.

Nunca é demais ressaltar que os deslocamentos de sentido funcionam também como armas estratégicas de governo, apagando tensões e obscurecendo a percepção dos limites que atravessam os processos políticos. Por isso, há que se problematizar, sobretudo, o diagnóstico de que toda crise da educação se constitui como uma crise de gestão, ou seja, uma crise da capacidade de gerir os processos educativos por parte dos atores envolvidos.

Esse argumento encontra sua significação plena no debate recente em torno de um novo modelo de intervenção pública voltada para a reforma dos aparelhos governamentais, que altera o modo de pensar a gestão de bens públicos, associando questões ligadas à eficiência e à produtividade econômica ao desempenho escolar ${ }^{12}$.

Mas, em que pese o desejo de abordar a penetração crescente da racionalidade da chamada Nova Gestão Pública (OLIVEIRA; ASSIS; LIMA, 2017, p. 514), na educação, a ênfase permanece sendo posta nos seus mecanismos de regulação e na crítica do modelo de governança. Identificam-se representações que favorecem a disseminação desses mecanismos ou a ela resistem, mas o

11 No Brasil, dentre outros, Lück (1998) tem defendido explicitamente que o conceito de gestão ultrapassa o de administração por “abranger uma série de concepções não abarcadas por este outro” (p. 16), defendendo que o uso do termo indica "a adoção de princípios e valores mais democráticos no ambiente escolar".

12 Pesquisas realizadas no âmbito da Revista Brasileira de Política e Administração da Educação (RBPAE), identificaram que o uso do termo gestão, nos textos publicados, começou em meados dos anos 1980, sobretudo após a "realização do Simpósio tendo a temática Democratização da educação e gestão democrática da educação" (MAIA, 2004, p. 147), identificando-se "sutilmente, a Administração com a centralização, com a ênfase na burocracia, relações antidemocráticas e a Gestão com práticas coletivas, relações horizontais e possibilidade de convivência democrática" (p. 157). No âmbito governamental a alteração terminológica ocorre desde o final da década de 1980 e início da década de 1990, materializando-se em diversos dispositivos normativos que enfatizam que as escolas, sobretudo as públicas, devem aplicar e desenvolver a gestão democrática em suas unidades, traduzindo sempre uma visão positivada do termo (CALIXTO, 2008, p. 28). 
alvo dos estudos permanece focalizado nas políticas e programas pensados como meios analíticos privilegiados para pensar os processos de apropriação da perspectiva gerencial, verificando-se em que medida a "implementação de um [dado] repertório de tecnologias e políticas" (p. 518) tem sido incorporado e quais as suas repercussões sobre as práticas dos atores e sobre os sistemas educacionais.

Contudo, raramente se problematizam as próprias categorias colocadas em jogo nesse debate. A tendência dos pesquisadores é a de assumir a priori que a noção de gestão, ao importar os valores e práticas da administração privada para a administração pública, descaracteriza, nesse percurso, a própria especificidade da ação educacional. Tudo se passa como se a indução da gestão, em sua vertente privada-mercantil, implicasse automaticamente uma oposição à lógica do direito e da democracia; lógica essa que estaria sendo pervertida com o capitalismo sendo apontado como o responsável pela deturpação de um sentido, suposto mais verdadeiro e autêntico, de gestão e de democracia.

Esse posicionamento analítico termina por opor uma "perspectiva tradicional (neoliberal)" e uma "perspectiva crítica" de gestão, esta última associada às "condições, mecanismos e espaços" (POLI; LAGARES, 2017, p. 835) em que os atores de uma sociedade democrática e participativa discutem e deliberam. Sem dúvidas, a adoção de práticas e saberes oriundos da administração privada possibilita a circulação e o uso de critérios da lógica empresarial no campo educacional. Entretanto, esse tipo de argumentação tende também a projetar diferenças fantasmáticas entre a racionalidade empresarial e a racionalidade educacional como se a organização escolar portasse, naturalmente, uma oposição quase metafísica a outras formas de organização social.

Nesse sentido, se, por um lado, não devemos diluir a especificidade da ação educativa, por outro, não devemos mitologizar os meios e os fins que regem o seu funcionamento. Essa postura idealiza o sentido da própria instituição escolar, reintroduzindo os princípios teológico-econômicos que lhe deram origem.

Nesse ponto, as investigações anarqueológicas desdobradas por Foucault e Agamben podem desempenhar um papel importante na elucidação de uma antiga aporia herdada pelos pesquisadores da administração educacional, que tendem a defender a especificidade da educação pela racionalidade dos seus fins. Ora, se a governamentalidade liberal ou neoliberal é uma "arte de administrar pessoas e coisas", sua assinatura teológica faz ser também a educação uma arte de administrar pessoas e coisas de acordo com um projeto, isto é, de acordo com 
um fim. Assim, a eficiência ou a produtividade demandada pela gramática política contemporânea define-se simplesmente pelo resultado final de uma ação, seja a maximização dos lucros ou a humanização pelo esclarecimento ${ }^{13}$.

A postura anarqueológica abdica de idealizar essa imagem juridificante do direito à educação e mesmo da democracia. Imagem que carrega em seu bojo uma visão salvífico-messiânica, ressaltando o deslocamento da gestão governamental para a economia política, a fim de elucidar o crescente empresariamento da vida humana e da subjetividade.

Nesse contexto, o papel da gestão educacional não consiste em apenas transferir os saberes e práticas da administração privada para a administração pública. Como a educação escolar já se encontra plenamente incorporada às tecnologias de controle da vida, o dispositivo gestionário pode, enfim, liberar plenamente sua função glorificante, convertendo os saberes e as práticas da administração educacional em veículos midiáticos do poder governamental. A prevalência dos paradigmas de gestão só se deixa apreender quando se leva em conta uma análise concreta da nova liturgia do poder. Esse aspecto decisivo é, no entanto, deixado à margem quando da compreensão do que se passa na subsunção da malha conceitual da administração educacional pelos paradigmas de gestão.

Como lembra Agamben (2011), a democracia contemporânea está inteiramente fundada na glória, ou seja, na gestão eficaz da aclamação, disseminada pelas mídias que assumem a direção dos processos de formação da opinião pública. A partir disso, a ênfase nos paradigmas de gestão assume um novo matiz, pois genealogicamente seus fundamentos são originariamente litúrgicos, trazendo para a modernidade uma forma de conceituação que visa a legitimar o formalismo prático e ritualístico das burocracias estatizadas.

A gestão da educação funciona, portanto, nos governos de direita ou de esquerda, como um processo gestual, reproduzindo performativamente as leis e os atos de governo que se fabricam, para a opinião pública, como sendo da ordem da necessidade. Parafraseando Agamben (2011), a gestão educacional representa uma zona de indiscernibilidade entre o geral e o particular, entre o

\footnotetext{
13 Não obstante, os teóricos da administração educacional tendem a privilegiar uma imagem do direito à educação forjada pelo racionalismo francês, que fecundou o pensamento dos revolucionários de 1789 , inaugurando de fato a democracia republicana, mas que, no fundo, é herdeira das categorias do direito canônico forjado entre os séculos XII e XIV, momento em que a terminologia administratio se aproximou de iurisdictio. Esquece-se, assim, que é o paradigma gerencial que abre o campo semântico do direito à educação tal como esse será articulado pela economia política capitalista e efetivado pelas técnicas administrativas, privadas ou públicas, que lhe são concernentes. Em outras palavras, não é capitalismo que distorce a administração e a gestão; foram essas categorias que formataram o capitalismo como uma insidiosa e penetrante tecnologia econômica-política de governo biopolítico dos indivíduos e das populações.
} 
calculado e o não desejado. Essa é sua economia ${ }^{14}$. Como consequência, urge outra postura teórica no seu tratamento, recuperando uma linguagem que privilegie a vida e a democracia desde a práxis política. Pois, como já sabiam os gregos, a vida democrática se conecta às práticas de liberdade, razão pela qual o âmbito doméstico (oikonômico) e o âmbito público (político) deveriam permanecer dissociados. Uma das críticas mais severas de Aristóteles à república platônica se baseava justamente no perigo da polis tornar-se uma gigantesca oikia, onde os cidadãos seriam mais administrados do que sujeitos de uma comunidade política.

Entretanto, "o que é interessante é que quando se chega aos teólogos cristãos, estes transformam o conceito de oikonomia no paradigma essencial" (AGAMBEN, 2004, p. 3). A autocompreensão da comunidade cristã nos termos de uma oikonomia, e não de uma política, gerou consequências decisivas para a configuração posterior da política e das teorias administrativas que passaram a legitimar a governamentalização da vida. Da teologia cristã derivaram, portanto, os dois paradigmas políticos do ocidente:

A teologia política, que baseia a transcendência do poder soberano no único Deus, e a teologia econômica, que substitui tal ideia com uma oikonomia, concebida como uma ordem imanente. Do primeiro derivam a filosofia política e a teoria moderna da soberania; do segundo, a biopolítica moderna, até o atual triunfo da economia [e dos paradigmas de gestão] sobre qualquer aspecto da vida social (AGAMBEN, 2004, p. 03).

Assim, em que pese a percepção de que não é possível "estabelecer na literatura especializada em administração diferenças substantivas entre esse conceito e o de gestão" (SILVA JÚNIOR, 2002, p. 202), consideramos que essa diferenciação é não apenas necessária, mas urgente. Pois as práticas da administração educacional no atual regime de acumulação capitalista operam mediante dispositivos que governam empresariando as formas de vida e as subjetividades, enquanto os paradigmas de gestão emergem como o arcano central do poder biopolítico, o mistério oculto e não revelado da encenação midiática e glorificante de processos políticos pseudodemocráticos e pseudoparticipativos.

14 Lê-se do apóstolo Paulo: “evangelizar para mim não é glória, senão necessidade (...) se o faço por imposição, é como um cargo de administração que me foi confiado” (1Cor 9, 16-17). Note-se que o apóstolo não se refere somente à sua atividade como imbuída de certa economia, mas também aos membros da comunidade messiânica com termos que pertencem ao vocabulário do gerenciamento doméstico, onde o próprio Cristo é referido como dono do oikos, e nunca com termos da política (AGAMBEN, 2011, p. 38). 


\section{CONSIDERAÇÕES FINAIS}

Por se tratar de uma pesquisa em curso, as conclusões só podem ser parciais. Contudo, não resta dúvida de que as investigações anarqueológicas de Foucault e Agamben, mesmo pouco difundidas junto ao campo acadêmico da administração educacional brasileira, fornecem pistas importantes para a problematização crítica de suas teorias. Talvez seja o tempo mesmo de se realizarem não apenas revisões ou estados da arte acerca da constituição ou das pesquisas que movem o campo, mas abrir efetivamente uma agenda de trabalho sobre seus fundamentos simultaneamente ontológicos e políticos, uma vez que o aprofundamento de suas matrizes conceituais da área é uma exigência vital.

Seja para integrar atores comumente invisibilizados nas decisões governamentais acerca dos rumos das políticas públicas de educação, seja para analisar os efeitos redutores provocados pela gestão midiática dos problemas educativos na atualidade, a elucidação das bases teóricas da administração e da gestão educacional é importante para desvelar sua dívida ontológica com uma racionalidade política que deriva diretamente da teologia cristã. Essa dívida explicita como a emergência dos saberes e das práticas da administração educacional surgem inseparáveis da própria noção de população, pensada como um rebanho a ser conduzido simultaneamente como objeto e sujeito de governos múltiplos.

Logo, a oposição entre administração e gestão educacional manifesta, na verdade, uma contraposição apenas aparente, pois a primeira se fundamenta na captura da subjetividade do povo como sujeito detentor do poder instituinte, enquanto a segunda recorre à glorificação midiática como forma de legitimar seus processos gestionários de controle da opinião pública. Ambas se conectam no exercício gerencial do poder, esvaziando o sentido da política, convertida em mero culto cerimonial que encarna aporeticamente a nova dimensão litúrgica dos poderes governamentais instituídos.

Tudo indica, portanto, que Chatterjee (2004) pode ter razão quando afirma que a noção de governamentalidade, além de mostrar o autoritarismo difuso nos atuais regimes de governo supostamente legítimos, prepara as condições efetivas para uma política dos governados ancorada na expansão das contracondutas democráticas. 


\section{REFERÊNCIAS}

ABDIAN, G.Z.; RIBEIRO, D.S.; MACHADO, L.M. A evolução do conhecimento em administração da educação no Brasil: suas raízes e processos de constituição teórica. Caxambu: ANPED, 2010. Texto apresentado no GT 05 Estado e política educacional.

AGAMBEN, G. O reino e a glória. São Paulo: Boitempo, 2011.

AGAMBEN, G. Estado de exceção. Homo sacer II. São Paulo: Boitempo, 2004.

ALGARTE, R. A. Produção de Pesquisas em Administração da Educação no Brasil: relatório final da pesquisa. Brasília: ANPAE. 1998. (Série estudos da ANPAE; $\left.\mathrm{n}^{\circ} 3\right)$.

ALONSO, M. O papel do diretor na administração escolar. SP, Difel, 1978.

AVELINO, N. "Governamentalidade e Anarqueologia". Revista Travessias, Rio de Janeiro, $\mathrm{n}^{\circ}$ 9, pp. 187-207. 2012

AVELINO, N. Michel Foucault: anarqueologia e ortologia dos saberes. V Congresso Internacional de Filosofia e Educação. Anais... Caxias do Sul, 2010.

BALL, S. J. Education Reform: A Critical and Post-structural Approach. Buckingham: Open University Press, 1994.

BALL, S. J. (ed.). Foucault and Education. London: Routledge, 1990.

BRUNO, Lúcia. Poder e administração no capitalismo contemporâneo. In: OLIVEIRA, Dalila Andrade. (Org.). Gestão democrática da educação: desafios contemporâneos. Petrópolis: Vozes, 1997.

CALIXTO, E. A. Mudança terminológica: administração x gestão. Revista de Iniciação Científica da FFC, v. 8, n.1, p. 18-30, 2008.

CANGUILHEM, G. Do social ao vital. In: O normal e o patológico. Rio de Janeiro: Forense Universitária, 2002, p. 209-229. 
CHATTERJEE, P. The politics of the governed: reflections on popular politics in most of the world. New York: Columbia University Press, 2004.

DEAN, M. Governmentality: Power and Rule in Modern Society. London: Sage, 1999.

EDWARDS, R. Mobilizing lifelong learning: governmentality in educational practices. Journal of Education Policy, v. 17, n. 3, 353-365. 2002.

DRABACH, N.P.; MOUSQUER, M.E.L. Dos primeiros escritos sobre administração escolar no Brasil aos escritos sobre gestão escolar: mudanças e continuidades. Currículo sem fronteiras, v. 9, n. 2, p. 258-285, Jul/Dez. 2009.

FELIX, M. de F. C. Administração Escolar: problema educativo ou empresarial? São Paulo: Cortez, 1989.

FOUCAULT, M. Do governo dos vivos. Curso no Collège de France, 19791980. São Paulo: Martins Fontes, 2014.

FOUCAULT, M. Vigiar e punir: nascimento da prisão. Petropólis: Vozes, 2013.

FOUCAULT, M. Do Governo dos Vivos. Curso no Collège de France, 19791980 (excertos). Tradução/transcrição, notas e apresentação de Nildo Avelino. São Paulo/Rio de Janeiro: CCS/Achiamé, 2010.

FOUCAULT, M. Segurança, território, população. Curso no Collège de France (1977-1978). São Paulo: Martins Fontes, 2008.

FOUCAULT, M. Omnes et singulatim - para uma crítica da razão política. Florianópolis: Nephelibata, 2006.

FOUCAULT, M. A governamentalidade. In: FOUCAULT, M. Microfísica do poder. Rio de Janeiro: Graal, 1992. p. 277-293.

GORDON, C. Governmental rationality: an introduction, in G. Burchell, C. Gordon and P. Miller (eds) The Foucault Effect: Studies in Governmentality. Hemel Hempstead: Harvester Wheatsheaf, 1991. 
HERVÁS, A.G. La Gloria y el concepto de lo político em Giorgio Agamben. Revista de Estudios Sociales, n. 35, Bogotá, pp. 66-77, abr. 2010.

KUENZER, A.Z. A teoria da administração educacional: ciência e ideologia. Cadernos de pesquisa. São Paulo, 48, pp. 39-46, Fev. 1984.

LEMKE, T. Foucault, governmentality and critique. paper presented at the Rethinking Marxism Conference, University of Amherst MA, 21-24 September 2000.

LÜCK, Heloisa et al. A escola participativa: o trabalho do gestor escolar. Rio de Janeiro: DP\&A Editora, 1998.

MAIA, G. Z. A. As publicações da ANPAE e a trajetória do conhecimento em Administração da Educação no Brasil. 2004. 196 f. Tese (Doutorado em Educação) -Universidade Estadual Paulista, Marília, 2004.

MAYER, P.P.; CANOPF, L. A correlação entre a administração geral e a administração escolar. Anais I Encontro Científico de Administração UTFPR Synergismus scyentifica. Pato Branco, 03 (1), 2008.

MESSAS, J.C.A. Administração da educação e administração pública: relações e implicações. 2007 257f Tese (Doutorado em Educação) - Universidade do Estado de São Paulo, Marília, 2007.

OLIVEIRA, D.; ASSIS, L.M.; LIMA, D.P. A Nova Gestão Pública no contexto escolar: internacionalização de uma agenda para a educação do século XXI. Revista Brasileira de Política e Administração Educacional, v. 33, n. 03, p. 707-728, 2017.

PARO, V. H. Administração escolar: introdução crítica. São Paulo: Cortez; Autores Associados, 1999.

PETERS, M.A. Truth-telling as an educational practice of the self: Foucault, parrhesia and the ethics of subjectivity. Oxford Review of Education, 29, 2, pp. 207-223. ago. 2003.

PETERS, M.A. Foucault and governmentality: understanding the neoliberal paradigm of education policy. The School Field, 12, 5-6, pp. 61-72. 2001. 
POLI, L.; LAGARES, R. Dilemas da gestão democrática da educação frente ao contexto da Nova Gestão Pública. Revista Brasileira de Política e Administração Educacional, v. 33, n. 3, p. 835 - 849, set./dez. 2017.

PORTOCARRERO, V. Instituição escolar e normalização em Foucault e Canguilhem. Revista Educação e Realidade, v. 29, n. 1, jan./jun., pp. 169-185, 2004.

RIBEIRO, J. Q. Ensaio de uma Teoria da Administração Escolar. São Paulo: Saraiva, 1978.

RIBEIRO, D.S.; MACHADO, L.M. Teorias da administração escolar em Querino Ribeiro e Lourenço Filho: raízes e processos de constituição de modelos teóricos. Revista Brasileira de Política e Administração Educacional, v. 23, n.1, pp. 13-28, jan/abr. 2007.

ROSE, N. Powers of Freedom: Reframing Political Thought. Cambridge: Cambridge University Press, 1999.

RUIZ, C. M. M. B. Giorgio Agamben, liturgia (e) política: por que o poder necessita da Glória? Revista Brasileira de Estudos Políticos, Belo Horizonte, n 108, pp. 185-213, jan./jun. 2014.

SANDER, B. A ANPAE e o compromisso com a Administração da Educação no Brasil. Revista Brasileira de Administração da Educação. Porto Alegre, v. 4, n¹, p.12-26, jan./jun.1985.

SANDER, B. Administração da educação no Brasil: evolução do conhecimento. Fortaleza: Edições UFC, 1982.

SILVA JÚNIOR, C. A. da. Espaço da administração no tempo da gestão. In: MACHADO, L. M.; FERREIRA, N. S. C. (Org). Política e gestão da educação: dois olhares. Rio de Janeiro: DP\&A Editora, 2002. p. 199-211.

SORDI, C. Da secularização à profanação: uma discussão a partir da genealogia teológica dos conceitos de governo e economia em Giorgio Agamben. Revista de Graduação, v. 6, n 1, p.1-79. 2013. 
TEIXEIRA, A. A administração pública brasileira e a educação. Revista Brasileira de estudos Pedagógicos. Rio de Janeiro: INEP, v.25, n. ${ }^{\circ}$ 63, p. 3-23. jan./mar. 1956.

TIKLY, L. Governmentality and the study of education policy in South Africa. Journal of Education Policy, 39, 2, 161-174. 2003.

TORRES, C. A. A política de educação não-formal na América Latina, Rio de Janeiro: Paz e Terra, 1992.

TRAGTENBERG, Maurício. Administração, poder e ideologia. São Paulo : Moraes, 1980.

TRAGTENBERG, Maurício. Burocracia e ideologia. São Paulo: Ática,1974.

WITTMANN, L.C. Administração da Educação hoje: ambiguidade de sua produção histórica. In: Em Aberto. Brasília, ano 6, n.36, out/dez, p. 1-7. 1987.

WITTMANN, L.C. Administração da educação: pressupostos e perspectivas para a relevância de sua prática. Perspectiva. Florianópolis, 1(5), p. 39-50. Jul/Dez, 1985.

ALEXANDRE SIMÃO FREITAS graduou-se em Pedagogia (1997), fez o mestrado em Educação (2000) e o doutorado em Sociologia (2005) pela Universidade Federal de Pernambuco. Atualmente é Professor Adjunto do Departamento de Administração e Planejamento Educacional (DAEPE) do Centro de Educação e professor permanente do Programa de Pós-Graduação em Educação (PPGE/ UFPE), na Linha de pesquisa em Educação e espiritualidade. Coordenou o GT 17 - Filosofia da educação da Anped (2013-2017).E-mail: alexkilaya@uol.com.br 